\title{
A PESQUISA SOBRE FORMAÇÃO DE PENSAMENTO TEÓRICO
}

Flávia da Silva Ferreira Asbahr ${ }^{1}$

O objetivo deste texto é sistematizar algumas contribuições da psicologia históricocultural à investigação sobre a formação do pensamento teórico no âmbito da educação escolar. Tomaremos como ponto de partida, mas também como questões para a estruturação do texto, as seguintes perguntas: Por que defender a escola como local privilegiado de formação do pensamento teórico?; Como se forma o pensamento teórico?; Como investigar sua formação?

O tema da formação de conceitos é central em Vigotski, e o autor debruça-se sobre a relação entre conceitos espontâneos e científicos, em sua clássica obra "A construção do pensamento e da linguagem" (2001). Davidov (1988), dando continuidade aos estudos vigotskianos, traz contribuições fundamentais à compreensão da formação do pensamento teórico, cujo conteúdo é a existência mediatizada, refletida, essencial, que reproduz as formas universais das coisas.

Para estudar o desenvolvimento dessa forma de pensamento, Davidov propõe a organização do que chama de experimento formativo, que é a criação de experimentos de ensino com o objetivo de acompanhar e avaliar o processo de aprendizagem e desenvolvimento dos estudantes. No Brasil, temos desenvolvido pesquisas sobre a formação do pensamento conceitual, tomando a Atividade Orientadora de Ensino (MOURA et al., 2010) como princípio metodológico. Pretendemos elucidar essas discussões no presente capítulo.

\section{Por Que Defender a Escola Como Local Privilegiado de Formação do Pensamento Teórico?}

A questão acima, em nossa análise, é fundamental em qualquer discussão sobre pesquisa educacional, cujo foco seja investigar processos de ensino e de aprendizagem de conceitos científicos. Temos como ponto de partida, que cabe a escola ensinar conteúdos e conceitos científicos, filosóficos e artísticos, ou, nos dizeres de Saviani (2000), cabe a escola ensinar conteúdos clássicos ${ }^{2}$. Defendemos, portanto, a especificidade da escola enquanto instituição,

\footnotetext{
${ }^{1}$ Professora Doutora - UNESP - Bauru - GEPAPE-FEUSP / LIEPPE (IPUSP e UNESP)

${ }^{2}$ Saviani (2000) define como clássico aquilo que resistiu aos embates do tempo, que permanece: “O clássico não se confunde com o tradicional e também não se opõe, necessariamente, ao moderno e muito menos ao atual. $\mathrm{O}$ clássico é aquilo que se firmou como fundamental, como essencial. Pode, pois, se constituir num critério útil para a seleção dos conteúdos do trabalho pedagógico". (SAVIANI, 2000, p. 13).
} 
cuja função social é garantir que as crianças e jovens possam apropriar-se das formas mais elaboradas e desenvolvidas de conhecimento.

Avaliamos que temos avançado na definição do que ensinar em diversas áreas de conhecimento. Mesmo com contradições e discordâncias, há certos consensos de quais seriam os conteúdos essenciais em cada área de conhecimento, e discussões consolidadas sobre o tema currículo escolar (DUARTE; PAGNONCELLI; MALANCHEN, 2016). Temos visto, ainda, a produção de currículos ricos de conteúdos em diferentes sistemas municipais e estaduais, tendo como exemplos, Cascavel-PR (PAGNONCELLI; DUARTE; MALANCHEN, 2012), BauruSP (PASQUALINI, 2018; CLAUDINO-KAMAZAKI; ASBAHR; MESQUITA, 2018), o Currículo Básico para a Escola Pública do Estado do Paraná ${ }^{3}$, entre outras propostas curriculares.

No entanto, nosso enfoque, neste momento, não é sobre o que ensinar, mas sobre o "para quê” ensinar conteúdos teóricos, matéria prima da formação do pensamento teórico. Propomos, assim, uma discussão sobre o caráter teleológico do conhecimento escolar.

A pergunta "para que ensinar conhecimentos teóricos na escola?" traz em seu bojo a concepção de qual sujeito queremos formar. E, nesse sentido, defendemos uma educação que prepare para além do mercado de trabalho, para além de ter um emprego, conforme é discutido por Paro (2001). Defendemos uma educação para o trabalho, entendido como primado ontológico à compreensão da humanização do homem. Ou, em outras palavras, o trabalho é a condição universal para que o homem torne-se humano, torne-se livre, ou, ao menos, veja a liberdade como horizonte possível ${ }^{4}$.

O que queremos destacar é que a apropriação de conhecimentos teóricos não pode ser um fim em si mesma, mas mediação para que os sujeitos, ao saírem dos limites do conhecimento cotidiano, possam compreender a realidade como totalidade (o que abarca suas contradições e historicidade), e, ao entendê-la, possam construir as condições para a emancipação humana da sociedade do capital, como postula Saviani (1980).

Em outras palavras, não podemos nos contentar com a formação de um sujeito que, do ponto de vista individual, parece ter pleno domínio dos conceitos aprendidos na escola, e os

\footnotetext{
3 Ver Noda e Galuch (2018) para detalhes sobre as políticas educacionais do Paraná.

${ }^{4}$ No campo marxista da educação há uma série de discussões sobre o trabalho como princípio educativo, mas a análise minuciosa da questão foge aos limites deste capítulo. Para um panorama geral do tema e acesso a outras referências recomendamos a leitura do verbete "Trabalho como princípio educativo", de autoria de Maria Ciavatta, no dicionário "Educação da Profissional em Saúde", disponível em: http://www.sites.epsjv.fiocruz.br/dicionario/verbetes/trapriedu.html, acesso em: 31 jul. 2020.
} 
verbaliza com precisão, mas que não consegue "usá-los" para entender o mundo e transformálo. Precisamos, portanto, ter muita clareza de qual sujeito queremos formar, o que significa compreensão da dimensão ética de nossa ação pedagógica em uma perspectiva da formação de uma "consciência de classe", de consciência como classe trabalhadora, o que, entre outras coisas, significa visão da totalidade da sociedade em suas contradições e a constituição de um projeto coletivo de sociedade organizada a partir dos interesses da classe trabalhadora.

Ensinamos para que nossos estudantes possam humanizar-se no processo de conhecer o mundo físico, social, cultural, e, nesse processo, possam se reconhecer como humanos que, por meio do trabalho, modificam (ou podem modificar) o mundo a sua volta. E, nesse sentido, há especificidades do papel da educação escolar, que é a transformação da consciência e a formação do pensamento teórico.

O desafio, que nos é apresentado, é como organizar um ensino que possa produzir mudanças qualitativas no desenvolvimento do pensamento dos estudantes, no sentido da formação do pensamento teórico e da apropriação do processo lógico e histórico que produziu a necessidade e a elaboração dos conceitos. Para tanto, faz-se necessário entendermos o que é o pensamento teórico e como este se forma.

\section{Formação do Pensamento Teórico Como Neoformação da Atividade de Estudo}

Um dos temas centrais de estudo de Vigotski foi a formação das funções psicológicas superiores, entendidas como funções especificamente humanas, caracterizadas por serem mediadas pelos signos e constituídas pela internalização das ações realizadas, no plano social, para as ações realizadas no plano psíquico:

Todas as funções psicointelectuais superiores aparecem duas vezes no decurso do desenvolvimento da criança: a primeira vez, nas atividades coletivas, nas atividades sociais, ou seja, como funções interpsíquicas; a segunda, nas atividades individuais, como propriedades internas do pensamento da criança, ou seja, como funções intrapsíquicas. (VIGOTSKI, 1988, p. 114).

Entre as funções estudadas, Vigotski dá destaque à relação entre pensamento e linguagem, especialmente em sua última obra, "A construção do pensamento e da linguagem" (2000). O autor debruça-se detidamente sobre o exame da constituição do pensamento conceitual e o define:

O pensamento conceitual é o meio mais adequado para conhecer a realidade porque penetra na essência interna dos objetos, já que a natureza dos mesmos 
não se revela na contemplação direta de um ou outro objeto isoladamente, mas por meio dos nexos e das relações que se manifestam na dinâmica do objeto, em seu desenvolvimento vinculado a todo o resto da realidade. O vínculo interno das coisas descobre-se com ajuda do pensamento conceitual, já que elaborar um conceito sobre algum objeto significa descobrir uma série de nexos e relações do objeto dado com toda a realidade, significa inclúi-lo no complexo sistema de fenômenos". (VIGOTSKI, 1996, p. 78-79, tradução nossa)

Considerando essa grande importância da formação do pensamento conceitual ao desenvolvimento psíquico dos sujeitos, Vigotski (2000) levanta a seguinte pergunta de pesquisa: "Como se desenvolvem os conceitos científicos na mente de uma criança em processo de aprendizagem escolar?” (p. 245). Em seus estudos acerca da relação entre pensamento e linguagem, o autor busca responder a esse questionamento. Para tanto, investiga as diferenças na gênese e no desenvolvimento dos conceitos espontâneos e científicos.

De forma sintética ${ }^{5}$, os conceitos espontâneos são formados no cotidiano, na comunicação direta da criança com os adultos, com base nos atributos puramente empíricos dos objetos. Portanto, a criança dificilmente consegue explicar o que entende por um conceito cotidiano, não pode defini-lo; não consegue, por exemplo, explicar o que é “irmão", apenas dá exemplos de irmãos que conhece. Segundo Vigotski, os conceitos espontâneos seguem o caminho de "baixo para cima", ou seja, são formados a partir da experiência cotidiana do sujeito com os objetos e, por meio da comunicação com os outros, há uma generalização e apropriação do significado do objeto (expresso na palavra).

Por outro lado, os conceitos científicos são formados na escola, por meio de um processo intencional, organizado e sistemático. Sua apropriação começa com a conscientização das características essenciais presentes na definição do objeto, em uma atividade de caráter consciente e intencional. São formados mediante procedimentos analíticos e não só com a experiência cotidiana. Segundo Vigotski, seguem o caminho de "cima para baixo", pois são apreendidos pelos símbolos, pelas generalizações teóricas, pela via do abstrato ao concreto.

Vigotski (2000) considera que os processos de formação dos dois tipos de conceito estão interligados. A base dos conceitos científicos são os conceitos espontâneos e, por outro lado, os conceitos espontâneos são reconfigurados e ampliados à medida que os conceitos científicos são aprendidos. Núñez (2009) sintetiza a relação dos conceitos espontâneos com os conceitos científicos e enfatiza o papel da escola na formação dos segundos:

\footnotetext{
${ }^{5}$ Em textos anteriores (ASBAHR, 2016, 2017) apresentamos de forma mais detalhada as relações entre conceitos espontâneos e científicos. Para entender mais sobre o tema, além do estudo do próprio autor (VIGOTSKI, 2000), recomendamos a leitura de Facci (2006), Nuñez (2009) e Martins (2013).
} 
Os conceitos espontâneos são categorias ontológicas que formam a base das teorias do senso comum sobre o mundo, intuitivas e próprias de cada indivíduo, que se desenvolve como um produto das experiências da vida cotidiana individual e social. Embora ricos em experiências práticas, esses conceitos são dependentes do contexto. Quanto aos conceitos científicos, podese afirmar que inserem-se nos sistemas de relações entre objetos definidos em teorias formais, formulados pela cultura científica para serem assimilados em processos pedagogicamente organizados no contexto escolar. (p. 44)

Davidov (1988), dando continuidade às proposições de Vigotski acerca da formação conceitual, tem, como ponto de partida de suas investigações, o seguinte pressuposto: a escola deve ensinar nossas crianças a pensarem teoricamente. Para o autor, a apropriação do conhecimento teórico é a forma universal do desenvolvimento psíquico humano. Davidov dedica-se, assim, à investigação da formação do pensamento teórico, neoformação específica da atividade de estudo ${ }^{6}$.

Para tanto, Davidov (1988) analisa também a formação do pensamento empírico e faz críticas contundentes à forma como o ensino escolar está organizado de forma hegemônica, em que predominam métodos de ensino baseados na dimensão empírica e utilitária do conhecimento, tendo como foco o ensino e a aprendizagem de conceitos empíricos e cotidianos. Tais procedimentos são organizados levando em conta o caráter visual direto, a percepção dos objetos. Os estudantes analisam, compararam e classificam diferentes objetos, buscando neles o que há de comum, as propriedades repetidas, estáveis, que parecem constituir-se como o essencial na definição dos objetos em análise. Nesse tipo de ensino, o pensamento ascende do sensorial-concreto para o mental-abstrato expresso na palavra, restringindo-se, assim, à abstração. Equivocadamente, pensamos que a capacidade para pensar abstratamente é o mais alto nível de desenvolvimento do pensamento.

Diferentemente, o pensamento teórico é a forma de pensamento que supera, por incorporação, o pensamento empírico, ou um pensamento baseado apenas na lógica formal. $\mathrm{Ou}$ seja, supera o pensamento que apenas categoriza ou nomeia os fenômenos. Segundo Davidov, o conteúdo do pensamento teórico é a existência mediatizada, refletida, essencial, que chega à essência dos conceitos e articula os conceitos em sistemas, em totalidades (DAVIDOV, 1988). Sua formação permite a inteligibilidade do real, a captação da realidade em seu movimento e

\footnotetext{
${ }^{6}$ Em Asbahr (2016), dedicamo-nos mais especificamente sobre a relação entre a formação do pensamento teórico e a formação da atividade de estudo. Sobre a formação do pensamento teórico, recomendamos a leitura de Rosa, Moraes e Cedro (2010a, 2010b); Sforni (2003); Libâneo (2004), além do próprio Davidov (1988).
} 
transformação, isto é, em sua historicidade, o que é essencial na formação da consciência de classe como mencionamos no primeiro item deste texto.

Ao atuar com o pensamento teórico, o sujeito opera com conceitos e não apenas com representações da realidade. Davidov (1988) explica, ainda, como o pensamento teórico ascende do abstrato ao concreto, permitindo a superação da compreensão aparente dos fenômenos como acontece com o pensamento empírico. O concreto aparece, portanto, como forma de síntese e não como ponto de partida. A tarefa do pensamento teórico é, por meio do procedimento de ascensão do abstrato ao concreto, compreender a realidade para além de sua aparência externa, isto é, revelar a essência do movimento do objeto.

No pensamento teórico, o concreto aparece duas vezes: como ponto de partida da contemplação e da representação, reelaboradas no conceito, e como resultado mental da reunião de abstrações. [...] Se, pelo contrário, o fenômeno ou objeto é tomado em unidade com o todo, é examinado em relação com suas outras manifestações, com sua essência, com a origem universal (lei), será um conhecimento concreto, mesmo que se expresse com a ajuda de signos mais "abstratos" e “convencionais". (DAVIDOV, 1988, p. 150-151, tradução nossa)

A compreensão acerca da gênese do pensamento teórico e a clareza sobre a finalidade da educação escolar em promovê-lo, trazem alguns desafios para a organização do ensino. Se quisermos produzir um ensino que promova o desenvolvimento do pensamento em sua máxima amplitude, não basta garantir que o estudante aprenda a verbalizar um conceito, mas que se aproprie do processo lógico e histórico que produziu a necessidade e a elaboração daquele conceito, e isso só ocorre se o sujeito estiver em atividade de estudo (ASBAHR, 2016).

Durante a palestra que deu origem a este texto, utilizamos um exemplo para entendermos como a formação do pensamento teórico está além da memorização e verbalização de um conceito, e significa compreender as relações históricas por trás de qualquer conteúdo. $\mathrm{Na}$ época (maio de 2019), o presidente Bolsonaro havia feito uma declaração polêmica sobre a educação no Brasil, dizendo que manifestantes estudantis eram "uns imbecis" que não sabiam a fórmula da água ${ }^{7}$, e, assim, justificando o corte de verbas para universidades públicas. A fala provocou inúmeras manifestações no país e destacamos uma delas, do Professor Helio da Silva Messeder Neto, da Universidade Federal da Bahia (UFBA), em rede social:

\footnotetext{
${ }^{7}$ Ver notícia de 15/05/2019, em https:/g1.globo.com/politica/noticia/2019/05/15/bolsonaro-diz-que-bloqueiaverba-da-educacao-porque-precisa-e-nao-porque-gostaria-mas-chama-manifestantes-de-idiotas.ghtml
} 
Bolsonaro sabe a fórmula da água?

Eu duvido. A gente pode achar que saber a fórmula da água é repetir H2O. Pronto. Permita-me discordar do presidente

Saber a fórmula da água é conseguir olhar para essa representação e reconhecer que nela se encontra a partícula formadora de um recurso natural do planeta que não está disponível para todos. Tá sendo privatizado.

É reconhecer que tem $\mathrm{H} 2 \mathrm{O}$ na lágrima da mulher preta que chora por seu filho morto. E chorar junto com ela. E não aceitar. E lutar para mudar isso

É saber que o conjunto de moléculas de água que não chega no sertão tem relação com a falta de políticas públicas e não com os limites naturais que nós já fizemos recuar.

Saber a fórmula da água é reconhecer que essa substância está presente na composição de uma porção de medicamentos que não chegam nos postos de saúde por falta de uma política que valorize o SUS.

Saber a fórmula da água é saber que esse líquido corre nas nossas veias e compõe o sangue. Sangue derramado todo dia por uma galera que insiste em lutar.

Caro Bolsonaro, quem sabia, de fato, a fórmula da água estava lá para lutar. Quem não sabia estava lutando pelo direito de saber. Lutava por uma educação que não ensina "apenas" a fórmula da água ou regra de três, mas a humanidade encarnada e as contradições em cada um desses conceitos

A gente sabe a fórmula da água. Mais do que você. Tem molécula $\mathrm{H} 2 \mathrm{O}$ na saliva que a gente não consegue engolir quando gritamos: "A nossa luta unificou, é estudante junto com trabalhador"

$\mathrm{Eu}$ não ensino meus alunos a recitarem $\mathrm{H} 2 \mathrm{O}$. Eu ensino o que essa representação significa para formar humanidade. (Postagem em rede social, em16/05/2019)

O professor Helio Messeder Neto traduz com profundidade a dimensão do pensamento teórico e sua importância à constituição da inteligibilidade do real para a classe trabalhadora: saber a fórmula da água (ou qualquer outro conteúdo) não significa recitá-la, mas entendê-la como representação humana e histórica.

Nesse sentido, a forma de ensinar e o conteúdo a ser ensinado devem formar uma unidade. Não se pode ensinar qualquer conteúdo, e os conteúdos não podem ser ensinados de qualquer maneira. Na perspectiva teórica adotada, a forma de ensinar também é conteúdo. Voltando à pergunta "para quê ensinar", se queremos formar um sujeito capaz de compreender teoricamente o mundo e a sociedade a sua volta de maneira a ter instrumentos para transformálos, também temos que pensar em formas de ensino que sejam transformadoras. A organização do ensino, nessa perspectiva, deve ser, portanto, tema central de nossas preocupações. Por ora, nos dedicaremos à discussão acerca da pesquisa sobre a formação de conceitos.

\section{A Pesquisa Sobre Formação de Pensamento Teórico}

Apresentaremos, primeiramente, alguns princípios metodológicos da Psicologia Histórico-Cultural, advindos do método materialista histórico dialético, que são fundamentais 
à investigação e análise dos dados de pesquisa, fundamentais também à pesquisa sobre a formação do pensamento conceitual.

Para Vigotski (1995), o método de conhecimento é parte essencial de uma concepção teórica: "O objeto e o método de investigação mantêm uma relação estreita" (p.47, tradução nossa). Segundo o autor, o método de conhecimento determina o objetivo da pesquisa, o caráter e a natureza da ciência, é premissa e produto, ferramenta e resultado de uma investigação.

Vigotski (1999) define o que é método e qual é sua relação com a produção de conhecimento a partir de uma perspectiva teórica definida, o materialismo histórico dialético, o que abarca uma lógica de conhecimento, a lógica dialética; uma concepção de homem, baseada na historicidade e na materialidade; e uma concepção de ciência, preocupada não em descrever a realidade, mas em explicá-la e transformá-la. Mas, segundo o autor, a aplicação direta do método materialismo histórico dialético à Psicologia não é possível, e Vigotski critica aqueles que fazem colagens das citações de Marx para explicar problemas que são próprios da Psicologia.

Como consequência, Vigotski constrói "uma concepção metodológica" a partir do método materialista histórico dialético. $\mathrm{O}$ autor propõe duas decorrências centrais desse método à Psicologia: alguns princípios metodológicos necessários à investigação dos fenômenos psicológicos humanos e o método de análise por unidades.

Vigotski (1995) anuncia três princípios metodológicos para a investigação dos fenômenos psicológicos, especialmente das funções psicológicas superiores: analisar processos e não objetos; explicar ao invés de descrever os fenômenos; e investigar os comportamentos fossilizados.

Além dos princípios metodológicos anunciados, Vigotski (2000) indica o método de análise por unidades como método necessário à análise dos fenômenos psicológicos. De acordo com o autor, tradicionalmente a Psicologia analisou seus objetos desmembrando-os em elementos. Decompõe-se o todo em partes e analisam-se essas partes de forma separada como se sua soma pudesse explicar a totalidade. Vale ressaltar que Marx (1989) já havia criticado esse procedimento e proposto a análise da totalidade no estudo da realidade. Vigotski parte do método marxiano e examina como as teorias psicológicas não dão conta da complexidade dos fenômenos psicológicos ao fragmentá-los em inúmeros segmentos.

Ao invés da decomposição em elementos, Vigotski postula uma análise que decomponha a totalidade em unidades. Define a unidade como o produto da análise que possui 
todas as propriedades inerentes ao todo, a parte indecomponível do todo que o explica por representar sua essência:

Procuramos substituir a análise que aplica o método de decomposição em elementos pela análise que desmembra a unidade complexa do pensamento discursivo em unidades várias, entendidas estas como produtos da análise que, à diferença dos elementos, não são momentos primários constituintes em relação a todo o fenômeno estudado mas apenas a alguns dos seus elementos e propriedades concretas, os quais, também diferentemente dos elementos, não perdem as propriedades inerentes à totalidade e são suscetíveis de explicação mas contêm, em sua forma primária e simples, aquelas propriedades do todo em função das quais se empreende a análise. (VIGOTSKI, 2000, p. 397-398)

Nesse sentido, Vigotski apropria-se do que Marx chama de procedimento de ascensão do abstrato ao concreto como movimento de apreensão do real. Para Marx (1989), o objeto só pode ser compreendido como totalidade, e não como somatória de partes, o que torna necessário investigar suas inter-relações dentro de um sistema. Essa integridade é chamada de concreto.

Adentrando-se na especificidade metodológica requerida ao estudo de seu objeto central, a gênese e o desenvolvimento das funções psicológicas superiores, Vigotski propõe um método particular de investigação que denomina de método genético-experimental (ou genético-causal, a depender da tradução) (VYGOTSKI, 1995, 1996), que consiste em estudar o psiquismo em seu processo de desenvolvimento, a partir da interferência planejada do pesquisador, que cria as condições para que as mudanças ocorram.

Vigotski centra suas investigações em objetos específicos da psicologia e, para que seus princípios metodológicos possam ser usados no campo da pesquisa educacional, são necessárias algumas mediações. A primeira delas é a análise de quais são os objetos específicos da pesquisa em educação, especialmente nessa relação com uma teoria psicológica como é a psicologia histórico-cultural. Rubinstein nos traz algumas pistas:

Consideramos que o mais importante para a prática das tarefas de investigação psicológica é descobrir o conteúdo psicológico interno da atividade humana o qual se manifesta e forma o homem, suas qualidades psíquicas. Para a prática pedagógica, a tarefa será descobrir o conteúdo psicológico interno da atividade da criança em curso no qual se realiza seu desenvolvimento e se formam suas qualidades psíquicas. (RUBINSTEIN, 1976, p. 201, grifos do autor, tradução nossa) 
Tomamos $^{8}$, como objeto central de investigação, a atividade pedagógica, entendida como unidade entre a atividade de ensino do professor e atividade de aprendizagem do estudante, tema que é melhor desenvolvido em Bernardes (2009), Moura et al. (2010) e Araújo e Moraes (2017). As últimas autoras sintetizam o que significa tomar a atividade pedagógica como objeto:

De modo geral poderíamos formular a seguinte tese: o estudo da Atividade Pedagógica, na perspectiva Histórico-Cultural, implica no estudo das relações entre o ensino e a aprendizagem que se estabelecem entre o significado social e o sentido pessoal (LEONTIEV, 1978) em relação ao conjunto de conhecimentos produzidos historicamente pela humanidade. Dessa afirmação desdobra-se a compreensão de que para conhecermos a Atividade Pedagógica em sua dimensão teórica é preciso investigar as relações entre os processos de objetivação e apropriação dos produtos materiais e ideais da atividade dos homens. Trata-se, assim, de investigar a relação entre o movimento lógicohistórico do conceito (explicitando a dimensão teórica da prática social que pôde ser objetiva nas diferentes esferas da vida) e os modos de ação possíveis e necessários para a apropriação de tais conceitos por cada sujeito singular. Essas relações essenciais da Atividade Pedagógica expressam-se e realizamse com base na unidade entre a atividade de ensino e a atividade de estudo. (ARAUJO; MORAES, 2017, p. 54, grifos das autoras).

Na investigação acerca da atividade pedagógica, a análise sobre a formação de conceitos é tema central. Nesse âmbito, destaca-se o experimento formativo enquanto procedimento metodológico e como uma particularidade do método geral genético-experimental. Vemos a proposta do experimento formativo, ainda não com essa nomenclatura, sendo delineada desde as investigações de Vigotski sobre o desenvolvimento psíquico, mas posteriormente definida e organizada por seus continuadores na seara da elaboração e da avaliação dos sistemas didáticos soviéticos ${ }^{9}$, conforme analisado por Longarezi (2019).

Davidov e Markova (1987) sintetizam o que é o experimento formativo:

Este método é uma das realizações particulares do método geral genéticocausal (ou genético-modelador) de estudo do desenvolvimento psíquico da criança, cujas bases encontram-se nos trabalhos de L. Vigotski e que logo foram multilateralmente ampliadas nos trabalhos de de A. Leóntiev, A. Luria, P. Galperin, A. Zaporózhets, D. Elkonin e seus colaboradores. A essência deste método expressa-se no estudo dos processos de transição a novas formas

\footnotetext{
${ }^{8}$ Tem-se como referência o coletivo de grupos de estudo e pesquisa intitulado Rede Gepape, cuja origem é o GEPAPE (Grupo de estudo e pesquisa sobre a atividade pedagógica), coordenado pelo Professor Doutor Manoel Oriosvaldo de Moura (FEUSP) desde 2002. O GEPAPe atualmente é constituído por uma rede de grupos de pesquisa de diversas regiões do Brasil. Os pesquisadores da rede buscam compreender os processos de aprendizagem dos sujeitos, sejam eles estudantes, professores ou gestores, produzindo orientações teóricometodológicas para a organização da atividade pedagógica. Em Moura (2010) e Moura (2017) há sínteses das produções dos grupos.

${ }^{9}$ Longarezi (2019) refere-se aos seguintes sistemas didáticos: Zankov; Galperin-Talizina; Elkonin-DavidovRepkin.
} 
de psiquismo, no estudo das condições de surgimento de um ou outro fenômeno psíquico e na criação experimental das condições necessárias para que surjam. (DAVIDOV; MARKOVA, 1987, p. 326, tradução nossa).

Como mencionado, os psicólogos e didatas soviéticos usavam os experimentos como procedimento metodológico para o desenvolvimento e avaliação dos sistemas didáticos (LONGAREZI; MOURA, 2017; LONGAREZI, 2019). Naquele contexto, eram criados experimentos de ensino com o objetivo de projetar, modelar e avaliar o desenvolvimento psíquico de estudantes e a experiência atuava ao mesmo tempo como método experimental de ensino e como proposta de investigação. Ou seja, eram produzidas intervenções intencionais no processo de ensino-aprendizagem para a compreensão, entre outros temas, do movimento de constituição do pensamento conceitual.

Davidov (1982) apresenta a característica essencial do experimento formativo como:

[...] o modelo ativo e a reprodução em condições singulares dos processos de surgimento e de estágios de desenvolvimento psíquico com o fim de revelar a essência deles. Graças a este método tem sido descobertas, por exemplo, as principais regularidades de desenvolvimento das formas de apropriação dos conhecimentos pelas crianças. (p. 446, tradução nossa)

No contexto soviético, o experimento formativo foi utilizado de diferentes maneiras, com distintas nomenclaturas e várias finalidades, a depender do momento histórico em que foi utilizado e do sistema didático em que estava inserido. Longarezi (2019) apresenta um interessante panorama histórico e teórico acerca do experimento formativo, com destaque para seu desenvolvimento no sistema Elkonin-Davidov-Repkin. Naquele caso, a proposta, de criar cientificamente sistemas didáticos promotores do desenvolvimento psíquico, fazia parte de políticas públicas educacionais, e escolas experimentais foram criadas.

Infelizmente, em nossa realidade brasileira, a realização de pesquisas sobre o desenvolvimento de conceitos, em nossos estudantes, tem ocorrido de maneira pontual e isolada, circunscrita, muitas vezes, ao âmbito de uma pesquisa de mestrado, de doutorado ou, no máximo, de uma investigação de um grupo de pesquisa em uma escola específica, mas raramente orientando a organização do ensino, propostas de formação de professores ou a definição de políticas públicas.

Tomaremos, como recorte, alguns exemplos de pesquisas, sobre a formação do pensamento teórico, inspiradas no experimento formativo, embora não necessariamente utilizem o termo para designar o experimento realizado. Na Rede Gepape (ver nota de rodapé 
8), temos desenvolvido pesquisas sobre o tema tendo a Atividade Orientadora de Ensino (AOE) (MOURA et al., 2010) como princípio para o ensino e para a pesquisa.

Segundo Moura et al. (2010), a AOE constitui-se como uma proposta de organização do ensino e da aprendizagem que, baseada na teoria histórico-cultural, apresenta-se "como uma possibilidade de realizar a atividade educativa, tendo por base o conhecimento produzido sobre os processos humanos de construção de conhecimento" (p. 208).

A AOE organiza-se de acordo com a estrutura da atividade proposta por Leontiev (1983). Tem uma necessidade, a apropriação da cultura, e um motivo, a apropriação do conhecimento historicamente acumulado. Realiza-se por meio de finalidades, ensinar e aprender, e de ações que consideram as condições objetivas da escola (MOURA et al., 2010). É, assim, unidade de formação do professor e do estudante.

[...] a AOE constitui-se em um modo geral de organização do ensino, em que seu conteúdo principal é o conhecimento teórico e seu objeto é a constituição do pensamento teórico do indivíduo no movimento de apropriação do conhecimento. Assim, o professor, ao organizar as ações que objetivam o ensinar, também requalifica seus conhecimentos, e é esse processo que caracteriza a AOE como unidade de formação do professor e do estudante. (p. 221)

$\mathrm{Na}$ AOE, a atividade dos estudantes é mobilizada a partir de uma situação desencadeadora de aprendizagem, que pode ser materializada por meio de diferentes recursos metodológicos, entre eles o jogo, as situações emergentes do cotidiano e a história virtual do conceito (MOURA et al., 2010).

A AOE também tem sido compreendida como instrumento metodológico, na pesquisa, acerca da atividade pedagógica, e como conceito para a organização da atividade de ensino. Constitui-se, assim, fonte de pesquisa e fundamento para o ensino (MOURA et al., 2010). Assim, são criadas situações de ensino que busquem reproduzir o movimento lógico-histórico do conceito e, ao mesmo tempo, são produzidas estratégias metodológicas para que esse movimento possa ser apreendido e analisado.

Seguem algumas referências de como a AOE tem sido usada como instrumento metodológico de pesquisa. Nascimento (2010) faz uma investigação didática, trazendo conteúdos circenses que podem ser trabalhados em educação física, artes e em outras disciplinas. Bernardes (2006) e Sforni (2003) realizam pesquisa sobre formação conceitual em experimento com ensino de geometria, com estudantes do $3^{\circ}$ ano de ensino fundamental. Sforni e Galuch (2006) analisam situações de ensino e aprendizagem sobre o tema alimentos. E 
poderíamos citar outros exemplos de pesquisas orientadas pelos professores Elaine Araújo Sampaio (USP), Vanessa Dias Moretti (UNIFESP), Anemari Roesler Luersen Vieira Lopes (UFSM), Marta Sueli de Faria Sforni (UEM), Silvia Pereira Gonzaga de Moraes (UEM), Marisa da Silva Dias (UNESP), Wellington Lima Cedro (UFG), Josélia Euzébio da Rosa (UNISUL), Ademir Damazio (UNESC), entre outros pesquisadores da Rede Gepape.

De forma a trazer um exemplo que materializa nossas discussões, tomaremos como referência a pesquisa de mestrado desenvolvida por Cybelle Cristina Ferreira do Amaral (2018), sob orientação de Marisa da Silva Dias, no Programa de Pós-Graduação em Docência para a Educação Básica, com o título "A significação do conceito matemático de área expresso por estudantes proveniente de uma Atividade Orientadora de Ensino" ${ }^{10}$. O objetivo da pesquisa era "compreender as significações manifestas por estudantes de um 5o ano do Ensino Fundamental, na aprendizagem do conceito matemático de área, por meio de uma Atividade Orientadora de Ensino, a partir no movimento lógico-histórico desse conceito".

A escolha dessa pesquisa justifica-se por inúmeras razões. Foi realizada por uma professora da rede pública, a autora da dissertação, no âmbito de suas atividades de ensino que foram organizadas de forma a serem unidade entre ensino e pesquisa. A autora fez um detalhado estudo histórico e lógico do conceito de área e incorpora o movimento lógico-histórico do conceito na organização das ações de ensino. Os procedimentos metodológicos para apreensão dos dados são organizados de forma cuidadosa: preparo dos materiais de ensino, organização dos espaços em sala de aula, criação de uma história virtual do conceito ${ }^{11}$ complexa que envolveu os alunos na situação de ensino, uso de vídeo-filmagens e de outras estratégias para apreender o movimento de apropriação do conceito pelos estudantes, criação de um caderno didático com a AOE de forma a orientar outros professores.

A proposta da pesquisa e de desenvolvimento da AOE foi organizada em dois encontros semanais de duas aulas cada, durante quatro semanas consecutivas. O problema de aprendizagem foi proposto a partir de uma história virtual sobre ocupação de terra para moradia e plantio, tendo como problematização inicial a necessidade humana de delimitação de porções de terra. Para tanto, Amaral (2018) constrói uma história que se passa na antiga Mesopotâmia em que o Rei da cidade de Ur convoca os agricultores para cultivar grãos às margens do Rio

\footnotetext{
${ }^{10}$ Dissertação disponível em https://repositorio.unesp.br/handle/11449/153739

${ }^{11}$ A história virtual do conceito refere-se à produção de uma narrativa que recria as condições essenciais de elaboração histórica do conceito a ser ensinado. A partir desta história, coloca-se o estudante em uma situaçãoproblema que revela o processo histórico de necessidade e produção do conceito (MOURA et al., 2010).
} 
Tigre, consideradas muito férteis. Para isso, teriam que dividir a terra em porções iguais a partir da seguinte contextualização, feita pela professora no papel de Rei:

Tenho percebido que as terras às margens do Rio Tigre apresentam uma condição muito favorável à agricultura e ao plantio dos grãos. Assim, venho aqui oferecer uma porção de terra a cada um de vocês, à margem do rio, entre estas duas curvas, porém, não tenho pessoas e instrumentos que possam me auxiliar nessa medição e fazer tal distribuição. Mediante essas condições, peço que encontrem uma maneira de dividir a terra igualmente, de modo que todos os senhores tenham a mesma porção, à margem do rio. Além disso, preciso lembrá-los de que, entre cada um dos terrenos, há a necessidade de deixarem um "corredor" de passagem de mesma largura, para que se possa fazer o transporte dos produtos cultivados e se permita a locomoção das pessoas que ali se fixarem. (AMARAL, 2018, p. 110).

Além da contextualização inicial, a docente-pesquisadora propõe algumas perguntas aos estudantes de forma a orientar suas ações de estudo: "Como os agricultores resolveram a dificuldade em dividir as porções de terra, de tal modo que todas elas tivessem a mesma superfície delimitada? Quais estratégias/instrumentos poderiam ser usados para realizarem tal delimitação?” (AMARAL, 2018, p. 110). A AOE foi organizada em quatro momentos:

1) apresentação aos estudantes do contexto histórico, geográfico e social em que se baseia a história virtual elaborada, bem como a problematização inicial, a fim de desencadear as possíveis soluções, de forma coletiva; 2) desenvolvimento de estratégias de delimitação e mensuração da superfície em estudo, por meio de instrumentos de medição não padronizados; 3) utilização de estratégias para definir a unidade de área como instrumento de mensuração de uma superfície plana; e, por fim, 4) sistematização dos conhecimentos elaborados, através do jogo com propósito pedagógico. (p. 107-108)

Para que os estudantes pudessem resolver a situação problema, Amaral, anteriormente, apresentou o contexto histórico trazido na história virtual, atribui nomes da região aos alunos de forma que se identificassem com a proposta, construiu uma representação do rio e suas margens para que os alunos pudessem testar suas hipóteses, planejou ações de ensino de forma a conduzir a apropriação do conceito pelos estudantes, como pode ser visto de forma detalhada na dissertação. Tais estratégias permitiram que a docente conhecesse as estratégias pessoais encontradas pelos estudantes e acompanhasse o movimento de apropriação do conceito de área no sentido da formação do pensamento teórico. Amaral (2018) conclui:

As significações expressas pelos estudantes, associadas ao conceito de área, foram elaboradas em diversos contextos, durante a intervenção, sob um movimento dialético, concebendo, a cada mediação, saltos qualitativos nas generalizações e no processo de apropriação dos estudantes em relação ao conceito de área, enquanto uma grandeza de superfície delimitada passível de 
de medida com instrumentos de caráter discreto, inicialmente e que por conta da necessidade humana em se medir transpõe-se a unidade contínua, configurada na realização do algoritmo da multiplicação, como é convencionalmente utilizado nas atividades práticas humanas e sistematizado no ambiente escolar. (p. 168-169).

Avaliamos que o trabalho apresentado materializa-se como expressão das possibilidades de um experimento formativo, por via da organização de uma AOE, para a investigação da formação do pensamento teórico tendo a teoria histórico-cultural e o materialismo históricodialético como nortes epistemológicos e metodológicos. Os dados de pesquisa revelam como os estudantes-sujeitos da investigação apropriaram-se do conceito de área para além de uma concepção verbalista e estabelecem relações entre os conceitos aprendidos com outros conteúdos e com outras situações vivenciadas fora do âmbito escolar.

\section{Algumas Considerações}

Buscamos, ao longo deste texto, trazer algumas contribuições à pesquisa sobre a formação do pensamento teórico, conceitual, tendo como referência teórica a psicologia histórico-cultural com fundamento epistemológico no materialismo histórico-dialético.

Pensar na organização da pesquisa, cujo objetivo é revelar o movimento de formação do pensamento conceitual dos estudantes (de educação infantil ao ensino superior) traz desafios, porque é muito difícil estudar o tema de forma artificial, fora do âmbito escolar, e, assim, será necessário programar ações investigativas, em unidade, com atividades de ensino. Por isso, trouxemos a Atividade Orientadora de Ensino como referência possível para a organização do ensino e como princípio metodológico à pesquisa em educação.

Por último, mas ao mesmo tempo central, voltamos a defender que a formação do pensamento teórico não pode ser um fim em si mesmo, mas mediação para constituição de um sujeito consciente, capaz de compreender o mundo a sua volta e transformá-lo no sentido de superação da sociedade do capital.

\section{Referências}

AMARAL, C. C. F. A significação do conceito matemático de área expressa por estudantes proveniente de uma atividade orientadora de ensino. 2018. $190 \mathrm{f}$. Dissertação (Mestrado em Docência para Educação Básica) - Faculdade de Ciências, Universidade Estadual Paulista, Bauru, 2018.

ARAUJO, E. S.; MORAES, S. G. Dos princípios da pesquisa em educação como atividade. In: MOURA, M. O. (org.). Educação escolar e pesquisa na teoria histórico-cultural. São Paulo: Loyola, 2017. p. 47-70. 
ASBAHR, F. S. F. Idade escolar e atividade de estudo: educação, ensino e apropriação dos sistemas conceituais. In: MARTINS, L. M.; ABRANTES, A. A.; FACCI, M. D. (org.).

Periodização histórico cultural do desenvolvimento: do nascimento à velhice. São Paulo: Autores Associados, 2016. p. 171-192.

ASBAHR, F. S. F. “Por que aprender isso, professora?" Sentido pessoal e atividade de estudo na Psicologia Histórico-Cultural. São Paulo: Editora Unesp, 2017. v. 1.

BERNARDES, M. E. M. Mediações simbólicas na atividade pedagógica: contribuições do enfoque histórico-cultural para o ensino e aprendizagem. 2006. $330 \mathrm{f}$. Tese (Doutorado em Educação: Ensino de Ciências e Matemática) - Faculdade de Educação, Universidade de São Paulo, São Paulo, 2006.

BERNARDES, M. E. M. Ensino e aprendizagem como unidade dialética na atividade pedagógica. Psicologia Escolar e Educacional, Campinas, v. 13, n. 2, p. 235-242, 2009. Disponível em http://pepsic.bvsalud.org/scielo.php? script=sci_home\&lng=en\&nrm=iso. Acesso em: 1 ago. 2010.

CLAUDINO-KAMAZAKI, S. G.; ASBAHR, F. S. F.; MESQUITA, A. M. Currículo comum para o ensino fundamental de Bauru-sp: em busca de articulação entre conteúdo e forma. Revista Espaço do Currículo, João Pessoa, v. 2, n. 11, p. 168-179, 2018.

DAVIDOV, V. Tipos de generalización en la enseñanza. Habana: Editorial Pueblo y educación, 1982.

DAVIDOV, V. La enseñanza escolar y el desarrollo psíquico: investigación teórica y experimental. Moscu: Editorial Progresso, 1988.

DAVYDOV, V.; MÁRKOVA, A. La concepcion de la actividad de estudio de los escolares. In: DAVYDOV, V.; SHUARE, M. La psicologia evolutiva y pedagogia en la URSS: antologia. Moscú: Editorial Progresso, 1987. p. 316-337.

DUARTE, N. S. M.; PAGNONCELLI, C.; MALANCHEN, J. (org.). O trabalho pedagógico nas disciplinas escolares: contribuições a partir dos fundamentos da pedagogia históricocrítica. Uberlândia: Navegando Publicações, 2016. v. 1.

FACCI, M. G. D. Vigotski e o processo ensino-aprendizagem: a formação de conceitos. In: MENDONÇA, S. G. L.; MILLER, S. (org.). Vigotski e a escola atual: fundamentos teóricos e implicações pedagógicas. Araraquara: Junqueira \& Marin, 2006. p. 123-148.

LEONTIEV, A. Actividad, conciencia e personalidad. Havana: Editorial Pueblo y Educacion, 1983.

LIBÂNEO, J. C. A didática e a aprendizagem do pensar e do aprender: a Teoria Históricocultural e a contribuição de Vasili Davydov. Revista Brasileira de Educação, Campinas, n. 27, p. 5-24, 2004.

LONGAREZI, A. M. Teoria do experimento formativo no sistema Elkonin-Davidov-Repkin. In: PUENTES, R. V.; LONGAREZI, A. M. (org.). Ensino desenvolvimental: sistema Elkonin-Davidov-Repkin. Campinas: Mercado de Letras, 2019. p. 161-212.

LONGAREZI, A. M.; MOURA, M. O. Intervenção didático-formativa como procedimento de pesquisa com ensino desenvolvimental. In: SIMPÓSIO DE PÓS-DOUTORADO DA FEUSP, 7., 2017, São Paulo. Resumos [...]. São Paulo: Editora da USP, 2017. 
MARTINS, L. M. O desenvolvimento do psiquismo e a educação escolar: contribuições à luz da psicologia histórico-cultural e da pedagogia histórico-crítica. Campinas: Autores Associados, 2013.

MARX, K. O método da economia política. In: FERNANDES, F. (org). Marx e Engels: história. São Paulo: Ática, 1989. p. 409-417. (Coleção Grandes Cientistas Sociais).

MOURA, M. O. (org.). A atividade pedagógica na teoria histórico-cultural. Brasília: Liber Livro, 2010.

MOURA, M. O. (org.). Educação escolar e pesquisa na teoria histórico-cultural. São Paulo: Edições Loyola, 2017.

MOURA, M. O. et al. Atividade orientadora de ensino: unidade entre ensino e aprendizagem. Revista Diálogo Educacional, Curitiba, v. 10, p. 205-229, 2010.

NASCIMENTO, C. P. A organização do ensino e a formação do pensamento estéticoartístico na Teoria Histórico-Cultural. 2010. 249 f. Dissertação (Mestrado em Educação) Faculdade de Educação, Universidade de São Paulo, São Paulo, 2010.

NODA, M.; GALUCH, M. T. B. Políticas públicas de educação no ensino básico do Estado do Paraná: da dívida social à formação para o mercado (1980-2000). Revista HISTEDBR On-line, Campinas, SP, v. 18, n. 2, p. 545-569, 2018. DOI: 10.20396/rho.v18i2.8652356. Disponível em:

https://periodicos.sbu.unicamp.br/ojs/index.php/histedbr/article/view/8652356. Acesso em: 23 nov. 2020.

NÚÑEZ, I. B. Vygotsky, Leontiev, Galperin: formação de conceitos e princípios didáticos. Brasília: Líber Livro, 2009.

PAGNONCELLI, C.; DUARTE, N. S. M.; MALANCHEN, J. A pedagogia histórico-crítica na trajetória histórica e nos fundamentos teóricos do currículo para a rede pública municipal de ensino de Cascavel/PR. Revista HISTEDBR On-line, Campinas, v. 12, n. 46, p. 190-204, 2012.

PARO, Vitor Henrique. Parem de preparar para o trabalho!!! Reflexões acerca dos efeitos do neoliberalismo sobre a gestão e o papel da escola básica. In: FERRETTI, Celso João; SILVA JÚNIOR, João dos Reis; OLIVEIRA, Maria Rita N. (Org.). Trabalho, formação e currículo: para onde vai a escola? São Paulo: Xamã, 1999. p. 101-120.

PASQUALINI, J. C. Proposta curricular para a educação infantil: a experiência de Bauru. Revista Espaço do Currículo, João Pessoa, v. 2, n. 11, p. 154-167, 2018.

ROSA, J. E.; MORAES, S. P. G.; CEDRO, W. L. As particularidades do pensamento empírico e do pensamento teórico na organização do ensino. In: MOURA, M. O. (org.). A atividade pedagógica na teoria histórico-cultural. Brasília: Liber livros, 2010a. p. 67-71.

ROSA, J. E.; MORAES, S. P. G.; CEDRO, W. L. A formação do pensamento teórico em uma atividade de ensino de Matemática. In: MOURA, M. O. (org.). A atividade pedagógica na teoria histórico-cultural. Brasília: Liber livros, 2010b. p. 135-154.

RUBINSTEIN, S. L. Problemas de psicologia general. Mexico: Grijaldo, 1976.

SAVIANI, D. Educação: do senso comum à consciência filosófica. São Paulo: Cortez; Autores Associados, 1980. 
SAVIANI, D. Pedagogia histórico-crítica: primeiras aproximações. 7. ed. Campinas: Autores Associados, 2000.

SFORNI, M. S. F. Aprendizagem conceitual e organização do ensino: contribuições da teoria da atividade. 2003. 166 f. Tese (Doutorado) - Faculdade de Educação, Universidade de São Paulo, São Paulo, 2003.

SFORNI, M. S. F.; GALUCH, M. T. B. Aprendizagem conceitual nas séries iniciais do ensino fundamental. Educar, Curitiba, n. 28, p. 217-229, 2006. Disponível em:

http://www.scielo.br. Acessos em: 4 jul. 2016.

VYGOTSKY, L. S. Aprendizagem e desenvolvimento intelectual na idade escolar. In: VYGOTSKY, L. S.; LURIA, A. R.; LEONTIEV, A. N. Linguagem, desenvolvimento e aprendizagem. 5. ed. São Paulo: Ed. Ícone, 1988. p. 103-117.

VYGOTSKI, L. S. Obras escogidas. Madrid: Machado Libros, 1995. v. 3.

VYGOTSKI, L. S. Obras escogidas. Madrid: Machado Libros, 1996. v.4.

VIGOTSKI, L. S. Teoria e método em psicologia. São Paulo: Martins Fontes, 1999.

VIGOTSKI, L. S. A construção do pensamento e da linguagem. São Paulo: Martins Fontes, 2000 . 